\title{
Ultimate load tests of slabs designed by the strip method
}

\author{
G. S. T. ARMER
}

Dr B. de V. Batchelor and Mr P. Y. Tong, Queen's University, Kingston, Canada The Author is to be congratulated on his attempt to provide experimental verification of the strip method of slab design.

33. The relatively high ultimate test loads as compared with the design ultimate loads are a significant feature of the test results. We agree that a factor other than the flexural behaviour of the slabs is responsible for the enhanced strength of the slabs. This, of course, is the compressive membrane action.

34. The Author's test results substantiate the conclusion derived from research done at Queen's University, Kingston, in which it was shown that compressive membrane action exists in two-way slabs supported by edge beams which could not be considered very stiff. This action was shown to enhance not only the flexural capacity of the slabs, but also their punching capacity.

35. The Queen's University programme, which was sponsored by the Department of Highways of Ontario, was designed to study the ultimate strength and behaviour of two-way continuous bridge slabs, supported by edge beams and subjected to concentrated loads. The reinforcement in the slabs was varied from zero to $0.725 \%$ in each direction. Although the boundary conditions and arrangement of reinforcement were different from those in the Author's tests, some similar behaviour in the two tests was observed.

36. The main similarity appears to be the presence of compressive membrane action, indicated by the appearance of tensile cracks in the restraining edge beams. This action was especially prominent in the early stages of loading, when no cracking had occurred in the slab, and while its behaviour was generally elastic. In some cases (lower reinforcement percentage) linear elastic behaviour was observed up to the design ultimate load.

37. The lack of cracking and small deflexion observed for slab T3 of the Author's tests, at the design ultimate load, are probably due to the compressive membrane effect rather than to conservative results to be expected from the strip method of design, as stated by the Author in $\S 20$. The very stiff edge beams used in this test would serve to promote the development of compressive membrane action.

38. Another similarity observed is the curtailment of the flat portion of the load/ deflexion curve for slabs failing in punching shear. Typical load/deflexion curves of the Queen's University slabs are shown in Fig. 18. As shown, the main difference between the two slabs is their behaviour after the limiting (maximum) compressive membrane action has been generated by the partial restraint of the edge beams. Further deflexion beyond this stage reduces the effect of membrane action.

39 . In the slabs having relatively high reinforcement ratio $(0.38 \%)$ it was possible to increase the load beyond this limiting state without collapse resulting. The applied load was then carried by a combination of flexural and compressive membrane action. This was not possible in the slab with low reinforcement ratio, because of its low moment capacity. The decrease in the compressive membrane effect could not be compensated by a corresponding increase in flexural action.

Paper published: Proc. Instn civ. Engrs, 1968, 41 (Oct.) 313-331. 


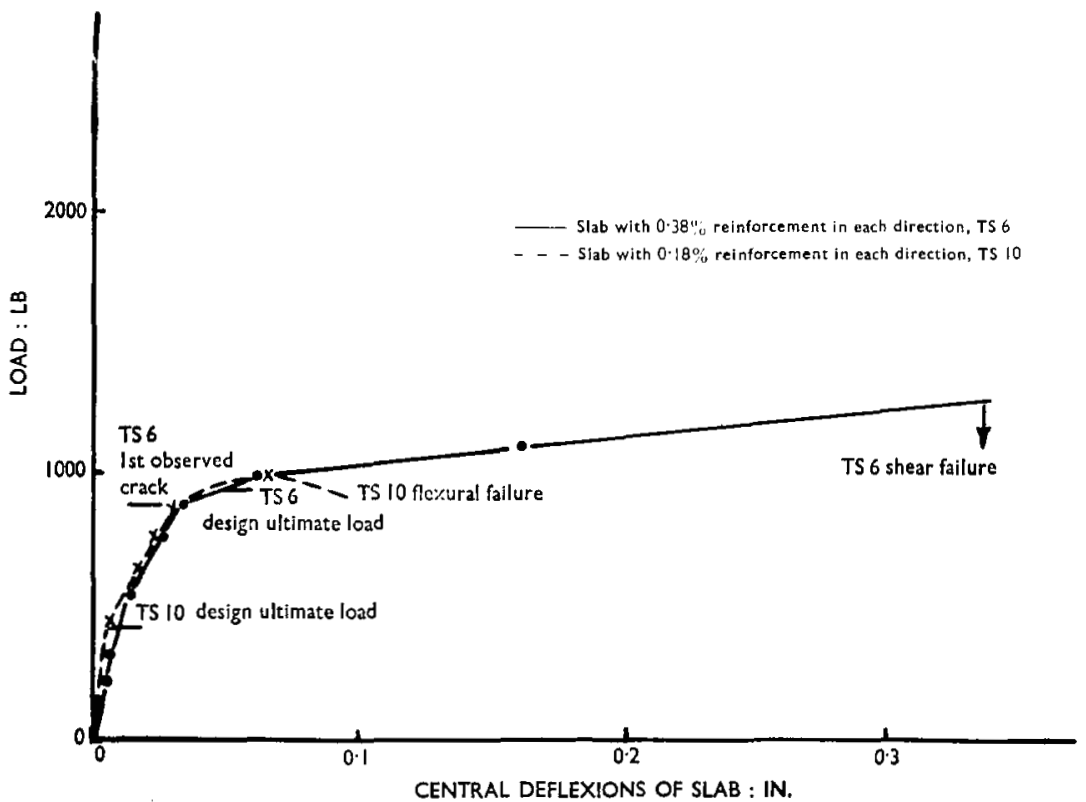

Fig. 18. Load/deflexion curve (for slabs at Queen's University)

Dr A. E. Long. Queen's University, Kingston, Ontario, and Dr D. Bond, Queen's University, Belfast

The enhancement effects of compressive membrane action on the punching load of a slab under a concentrated loading, if they could be taken into account in analysis, would probably lead to considerable benefits in economy. In view of this, the comments of the Author in $\$ 29$ were of interest to us, as we consider that future punching tests should attempt to simulate boundary conditions more closely than those tests carried out in the past. This conclusion was reached after a study of the results of a number of tests carried out at Queen's University, Belfast, on quarterscale models. ${ }^{7}$

41. In these tests considerable efforts were made to simulate as closely as possible the boundary conditions which would exist in practice around an interior column in a flat slab structure. Basically a square element of slab extending from the column to mid-span was considered. A system of 16 point loads simulating a uniformly distributed vertical loading was applied to the slab by means of a hydraulic jack which reacted against the column. In addition a moment could be applied to the column by horizontal jacks at its extremities, and, in order to satisfy the boundary conditions, the edges of the slab were restrained against rotation. This was done as accurately as was experimentally possible, in such a way that the edge slopes of opposite sides of the slab were maintained parallel. Further details of this system are given in Reference 7.

42. As a result of these tests it was observed that compressive membrane action did not produce a significant enhancement to the punching resistance when the slab was subjected to uniform vertical loading alone. This also appears to hold for the tests carried out by Guralnick and $\mathrm{LaFraugh}^{\mathrm{B}}$ on the nine-panel model which failed 
by punching at an interior column. Thus it would appear that the simplified testing arrangement of supporting the slab around the assumed line of contraflexure is justified for the vertical loading case.

43. However, when the test specimens in Belfast were subjected to combined vertical and transfer of moment type loading, as might be caused by earthquake, wind or unsymmetrical floor loading, considerable compressive membrane action was in evidence. In fact, from the results of the tests, an enhancement of $60-80 \%$ was estimated relative to the punching load predicted, whereas in similar tests carried out by $\mathrm{Moe}^{9}$ no enhancement was apparent, possibly because the slab was simply supported around the assumed line of contraflexure for vertical loading. Thus it would appear that greater attention should be focused on the simulation of the boundary conditions, especially in this combined loading case, to allow for the possible development of compressive membrane action.

Mr D. E. Charrett and Mr R. E. Melchers, Monash University, Clayton, Victoria, Australia

Mr Armer's Paper shows convincingly that the Hillerborg method of slab design is a simple and straightforward procedure resulting in slabs which behave satisfactorily at all load levels up to collapse. It is quite evident that the strip method is a much more powerful design procedure than that based on yield-line theory. It lends itself to the solution of problems intractable by the theory of elasticity and those for which yield-line theory is complicated. Furthermore, it provides the theoretical basis for the intuitive ideas of most practising engineers but does not require more than an elementary knowledge of beam theory.

45. In practice, slab sections are under-reinforced with an extended yield plateau. The elastic region is fairly steep and is only of significance at loads less than the design failure load. We feel, therefore, that the assumption of rigid-plastic behaviour (Fig. 1) is not necessary.

46. Hillerborg's method can be readily used to minimize the quantity of reinforcement. However, the position of the discontinuity lines depends on whether the steel is curtailed or uncurtailed along its span. ${ }^{10}$ If the steel is curtailed, the stress field which gives the minimum moment volume has the least reinforcement. In a rectangular simply supported slab, the discontinuity lines for minimum moment volume are rectangular hyperbolae. ${ }^{11}$

47. The Author states that all steel was uncurtailed $(\S 6)$. The discontinuity lines for slab T1 for minimum uncurtailed steel have been shown by Rozvany ${ }^{12}$ to be straight lines which obey the relationship $\mu=\tan \theta$. This does not agree with Fig. 4, which is derived for minimum moment volume.

48. Sharpe and Clyde ${ }^{13}$ have reported tests on slabs designed by the strip method and have compared them with yield-line solutions for a number of boundary conditions. Rozvany ${ }^{14}$ has tested the optimum and yield-line solutions for a square, simply supported slab. These authors all found that slabs designed by rational methods showed satisfactory behaviour as regards cracking behaviour and ultimate load.

49. We concur with the Author in his assessment of the behaviour of slabs designed by the strip method. Tests performed by M. A. Muspratt at Monash University on $10 \mathrm{ft}$ square, $3 \frac{1}{4} \mathrm{in}$. thick, simply supported slabs reinforced with $\frac{1}{4}$ in. dia. mild steel rods have shown satisfactory behaviour at all stages of loading.

50. A load/deflexion plot for four slabs tested recently is shown in Fig. 19. The solutions tested were $(a)$ a uniform isotropic mesh of one layer, designed on the basis of yield-line theory, $(b)$ an uncurtailed Hillerborg design, in which only the bar spacing was varied, and (c) two absolute optimum designs based on the moment fields obtained by Rozvany ${ }^{14}$ and by Morley. ${ }^{15}$ The reinforcement layouts are shown in Fig. 20.

51. In general, the behaviour of the slabs was very similar at loads below working 


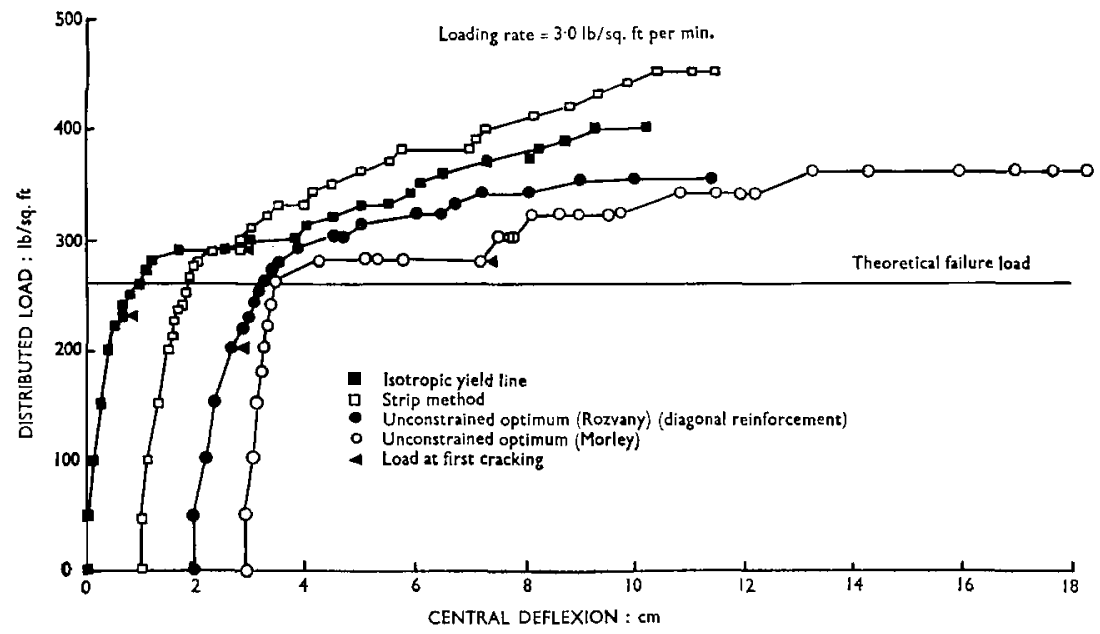

Fig. 19. Load/deflexion curves

load. At higher loading, cracking occurred first in the Rozvany solution, then in the yield-line solution, but not until the design failure load had been reached did cracking of the other two designs occur.

52. Deflexions below the design failure load were generally similar, although the Rozvany solution was found to be less stiff and the Morley solution slightly stiffer than the others.

53. It is interesting to note that the uncurtailed Hillerborg solution had the highest overload capacity, whereas the absolute minimum weight solutions of Rozvany and Morley gave very similar, although lower, results.

54. In all tests, initial yield was followed by tensile membrane action, and the observation by the Author of cracking penetrating the slabs at higher loading was also evident in the Monash tests.

55. The Author's loading arrangement consisted of a series of equal point loads over the slab, whereas the Monash tests used an air pressure loading arrangement which loaded the slabs uniformly from underneath. We feel that such an arrangement may be more in keeping with the design assumptions and obviates the need to penetrate the slab at a larger number of points. The testing arrangements at Monash have been described by Rozyany. ${ }^{14}$

56. Recently, experimental work at Monash University to study the behaviour of axisymmetric slabs designed using the Hillerborg approach has shown that these too behave satisfactorily under most loading systems.

57. We agree with the Author that reinforcement layouts using the Hillerborg method (in particular optimized solutions) can result in rather unconventional patterns.

\section{Mr Armer}

I should like to thank the contributors to the discussion for their interesting letters. The points concerning membrane action in slabs, which they have taken up, are of importance not only for the development of new theories of slab design but also for an understanding of the shortcomings of existing theories. ${ }^{16}$

59. It is worth while briefly reviewing the situations in which membrane action 


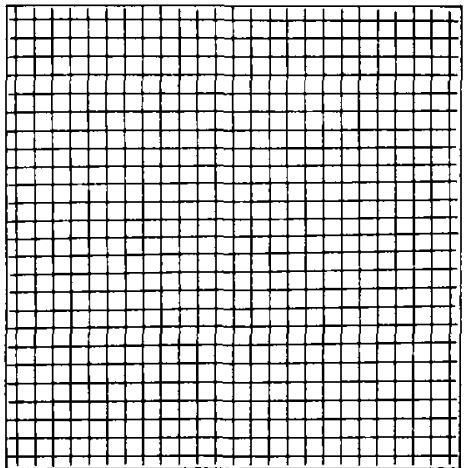

(a)

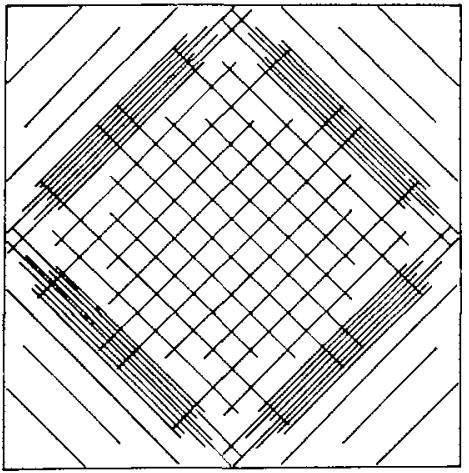

(c)

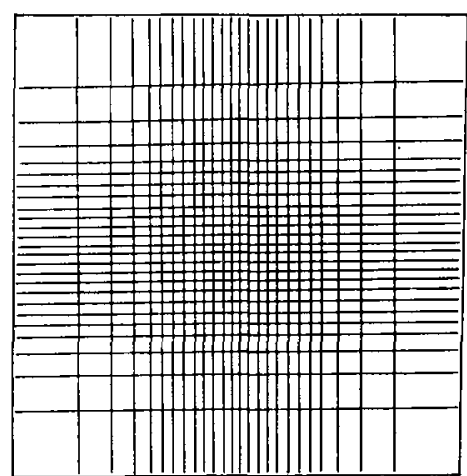

(b)

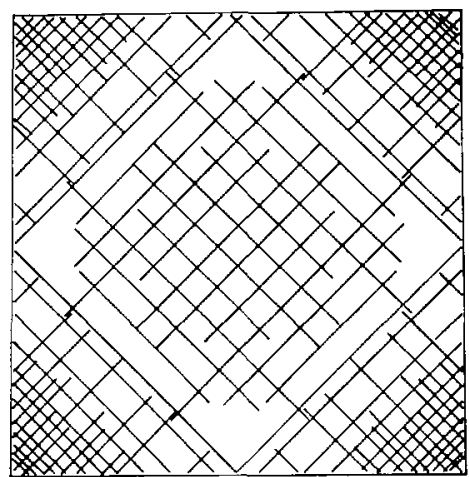

(d)

Fig. 20. Layout of reinforcement

occurs. As it happens, it is somewhat easier to define when membrane stresses will not occur in slabs. For a slab to have zero membrane stresse $\mathrm{s}^{17}$ it must deform into a developable surface and satisfy the onerous condition:

$$
\left(\frac{\partial^{2} \omega}{\partial x \partial y}\right)^{2}-\frac{\partial^{2} \omega}{\partial x^{2}} \cdot \frac{\partial^{2} \omega}{\partial y^{2}}=0
$$

This condition is derived from Von Karman's large deflexion equations. ${ }^{18}$ The converse, however, is not true and a slab deformed into a developable surface is not necessarily devoid of membrane stresses. This limits, even further, the number of slabs where there are no membrane stresses.

60. It is unfortunate that the published research work on membrane stresses has concentrated on the two extreme states of compressive and tensile membrane action, and little or no attention has been paid to the vast intermediate range. These are of the sort reported in reference 19 , and a common situation in which they might occur is in flat slab construction, where in the elastic range the slab will try to deform into a sheet corrugated in two directions, the tops of the corrugations at midspan acting as compression zones and the troughs as tensile zones.

61. The three factors, membrane action, flexural behaviour and punching shear 
are interdependent. The type and degree of membrane action will depend on the loading and support conditions and the shape (both plan and cross sections) of the slab. The flexural strength will generally be improved in a compressive membrane field. The punching shear strength will decrease as the amount of cracking due to flexure increases. Therefore if membrane action improves the flexural strength it will also aid the punching strength, unless the initial shear failure load is much below the flexural failure load.

62. I should like to draw the attention of Dr Batchelor and Mr Tong to the fact that the compressive membrane effect was equally in evidence in those slabs in which edge beams were not used.

63. I am not convinced by the examples cited by Drs Long and Bond in $\S 42$. The shear failure in Guralnick and LaFraugh's slab only occurred after extensive flexural cracking over the column. This would obviously considerably reduce the local shear strength.

64. Regarding their comments on membrane action with combined vertical and horizontal loading, Dr H. G. Russell has tested some four and six column flat slab models under combined loading at the Building Research Station. As none of them had a true internal column, there was little evidence of membrane action, which shows that membrane action is more dependent on layout of columns than presence of horizontal load.

65. In reply to Messrs Charrett and Melcher, Fig. 4 applies to slabs with curtailed steel and straight discontinuities. The relationships between moment volume, $\theta$ and $\mu$ were given in such detail to show that for most practical slabs, the value of the angle $\theta$ is not critical, i.e. it does not significantly affect the moment volume. This figure was only used as a general guide for the design of slab T1.

66. The results of their tests are quite interesting and apparently justify the use of extreme optimization; however, it would be wise to test other shapes, since the square slab is particularly prone to develop membrane action. ${ }^{16}$

67. Many slabs have been tested using loading equipment similar to that described in the Paper, and none of these has obviously been affected by having small holes through it. The benefits of ready access to both surfaces seem to outweigh any small disadvantages of this system of loading.

\section{References}

7. Long A. E. Punching failure of reinforced concrete slabs. PhD Thesis, Queen's University, Belfast, 1967.

8. Guralnick S. A. and LAFraugh R. W. Laboratory study of a $45 \mathrm{ft}$ square flat plate structure. J. Am. Concr. Inst., 1963, 60 (Sept.) 1107-1185.

9. MOE J. Shearing strength of reinforced concrete slabs and footings under concentrated loads. Bulletin D47, Portland Cement Association, Research and Development Laboratories, 1961 (April) 1-130.

10. Charrett D. E. and Melchers R. E. in Wood R. H. and Armer G. S. T., The theory of the strip method for the design of slabs, Discussion, Proc. Instn civ. Engrs, 1969, 43 (June).

11. Clyde D. H. and Sharpe R. in Rozvany G. I. N., Optimum synthesis of prestressed structures, Discussion. Proc. Am. Soc. civ. Engrs, 1965, 91 (ST4) 236-241.

12. Rozvany G. I. N. Rational approach to slab design. J. Proc. Aust Chem. Inst. 1966 (10) 1077-1094.

13. Sharpe R. and Clyde D. H. The rational design of reinforced concrete slabs. Civ. Engng Trans. Instn Engrs Aust., 1967, CE9 (2) 209-216.

14. Rozvany G. I. N. The behaviour of optimized reinforced slabs. Ibid., 283-294.

15. Morley C. T. The minimum reinforcement of concrete slabs. Int.J. mech. Sci., $1966,8,305-319$. 
16. Woon R. H. A partial failure of limit analysis for slabs and the consequences for future research, to be published in Mag. conc. Res.

17. MANSFieLd E. H. The inextensional theory for thin flat plates. Q. J. mech. appl. Maths., 1955, 8 (3) 338-352.

18. TIMOSHENKO S. and WOINOWSKY-KRIEGER S. Theory of plates and shells. McGraw-Hill, 1959, 417.

19. ARmer G. S. T. in Jacobson A., Membrane-flexural failure modes of restrained slabs, Discussion. Proc. Am. Soc. civ. Engrs, 1968, 94 (ST7) 1836-1838. 